\title{
Educação, narrativa e experiência
}

\section{Education, narrative and experience}

Eloiza Gurgel Pires ${ }^{1}$

\begin{abstract}
Resumo
Contrapondo-se ao saber científico e a um empobrecimento cultural gerado pelo conhecimento instrumental, homogeneizante já nas primeiras décadas do século XX, Walter Benjamin alertava para a importância da experiência narrativa como condição da historicidade do ser humano. De acordo com esse autor, a dificuldade de intercambiar experiências e, consequentemente, o declínio da arte de narrar no mundo moderno, alteraram os modos de sentir e de saber do sujeito em formação. Este tem sua experiência subtraída pelo tempo linear esvaziado de sentido, homogêneo e cronológico, pelo acúmulo de informações e saberes, pelo bombardeio das "novidades" geradas nos meios comunicativos e por uma ação formadora, fundada no pensamento empíricotécnico. Este artigo discute o declínio da experiência e o desaparecimento da narrativa tradicional, retomando os limiares benjaminianos nos escritos e nos espaços de errâncias, que condensam o pensamento do filósofo em torno do processo de modernidade e suas implicações no campo educativo.
\end{abstract}

Palavras-chave: Educação. Narrativa. Experiência. Modernidade.

\begin{abstract}
Walter Benjamin was opposed the scientific knowledge, and cultural impoverishment generated by instrumental knowledge, homogenizing, in the early decades of the twentieth century. Then he warned about the relevance of the narrative experience as a condition of the historicity of the human being. According to this author, the difficulty of interchange experiences and consequently the decline of the art of storytelling in the modern world have changed the ways of feeling and knowing the subject in formation. The experience of this subject was taken away from him by a meaningless linear time, homogeneous and chronological, by the accumulation of information and knowledge, by the bombardment of the "news" created in the means of communication and by an action, established on the empirical thinkingtechnical. This article discusses the decline of the experience and the disappearance of the traditional narrative, taking back the thresholds benjaminian in the writings and in the wandering spaces that condense the philosopher's thought about the process of modernity and its implications in the educational field.
\end{abstract}

Keywords: Education. Narrative. Experience. Modernity.

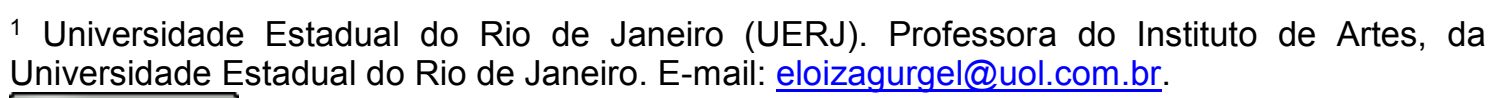




\section{0 declínio da arte de narrar}

Desde a Odisséia de Homero, paradigma primeiro das buscas e das errâncias humanas, o modo como o sujeito se constitui na linguagem, em um processo de criação-nomeação do mundo, implica em como esse sujeito significa as suas experiências, isto é, como ele as traduz. Essa questão se refere aos modos como a humanidade se conta a si mesma, se recria na tradição. Segundo Bornheim (1972), esse termo tem origem no latim - traditio, verbo: tradire, e significa entregar. Em suas palavras: "designa o ato de passar algo a outra pessoa, ou de passar de uma geração a outra geração"; está relacionado também ao conhecimento oral e escrito: "através da tradição, algo é dito e o dito é entregue de geração em geração" (BORNHEIM, 1972, p. 18). Esse movimento se dirige ao outro, e mergulha o indivíduo no tempo da coletividade.

Com as Guerras Mundiais e a crença na razão e no progresso, houve no mundo moderno uma redução drástica da experiência do tempo, o que repercutiu nos modos dos indivíduos se relacionarem e de traduzirem as suas experiências. A busca exacerbada pelo novo passou a ser um imperativo que anunciava a morte do sujeito clássico e a desvalorização de todo um patrimônio cultural. Da ruptura com o passado, decorre a impossibilidade de toda memória comum, a degradação da experiência coletiva, o fim das formas seculares de transmissão e comunicação de saberes. Por outro lado, do ponto de vista do materialismo histórico, daí decorre também o desejo de romper com a história escrita pelos vencedores; a história que ignorou o sofrimento dos explorados e oprimidos.

Nas primeiras décadas do século $\mathrm{XX}$, as vanguardas históricas traziam novas propostas artísticas que compartilhavam da atitude de repúdio à tradição, em um desejo de renovação. Valores que até então eram tidos como inquestionáveis passam a ser postos em xeque suscitando transformações sociais, políticas e econômicas paralelamente ao desenvolvimento do pensamento filosófico e científico. Concomitante a esse desejo de renovação em praticamente todos os campos, há o colapso de sistemas e valores autoritários tradicionais em face do fortalecimento dos partidos socialistas com 
o apoio das classes trabalhadoras (é um acontecimento emblemático a Revolução Russa de 1917). Segundo o historiador Hobsbawm (2008),

parecia óbvio que o velho mundo estava condenado. A velha sociedade, a velha economia, os velhos sistemas políticos tinham, como diz o provérbio chinês 'perdido o mandato no céu'. A humanidade estava à espera de uma alternativa (HOBSBAWM, 2008, p. 62).

Nas "Teses sobre o conceito de História", Benjamim revela o caráter ambivalente da tradição.

Não existe documento de cultura que não seja ao mesmo tempo um documento da barbárie. $E$, assim como a cultura não é isenta de barbárie, não o é, tampouco, o processo de transmissão da cultura. Por isso, na medida do possível, o materialista histórico se desvia dela. Considera sua tarefa escovar a história a contrapelo (BENJAMIN, 1996, p. 225).

Desse modo, "o esvaziamento da tradição", portanto, "não é necessariamente um mal, pois enquanto arquivo da injustiça, ela contribui, de certo modo, para perpetuá-la" (ROUANET, 1981, p. 52). A tentativa de Benjamin será a de retomar o que foi desprezado e esquecido pela ordenação linear da história e pela lógica do progresso. Seu desafio é o de construir uma história a "contrapelo", que corresponda à verdade daqueles a quem a tradição da dominação fez calar. Nesse sentido, o futuro, para o filósofo, não é uma projeção do tempo na linha evolutiva da história, mas o seu desvio em direção ao passado. Assim é que ele retoma a tradição dos antigos narradores que compartilhavam histórias e experiências em um mundo arcaico ignorado pela história oficial. A radicalidade do pensamento benjaminiano consiste fundamentalmente na construção do presente, isto é, na tarefa de retomar, em um "aqui e agora", aquilo que foi soterrado nas ruínas do continuum da história, numa perspectiva transformadora. Para Benjamin, a tradição é inspiração para a criação do radicalmente novo, reabrindo o tempo histórico e suas possibilidades perdidas.

Em seu ensaio sobre o escritor Nikolai Leskov, a figura do narrador está ligada aos ofícios do mundo antigo e medieval. Na fonte criativa do narrador, está a "experiência que vai de boca em boca" (BENJAMIN, 1996, p. 198), a mesma que serve como matéria prima às narrativas escritas, que se apropriam 
dos traços da oralidade. O narrador é tanto aquele que conta sobre o que lhe aconteceu em cidades e países distantes, a partir de suas viagens, como o que não se desloca da sua aldeia, mas tem muito o que contar da história e da tradição de sua terra. Neles estão, respectivamente, o marinheiro e o camponês. Para Benjamin, "a real extensão do reino das narrações não é pensável em todo seu alcance histórico sem a íntima interpenetração destes dois tipos arcaicos" (1996, p. 1999). O encontro entre essas duas linhagens de narradores se dará nas corporações de ofício onde o aprendente viajante e o mestre sedentário trocarão experiências: no trabalho medieval o saber sobre o distante se une com o saber sobre o passado do sedentário. Nikolai Leskov, escritor ao qual Benjamin atribui a figura do narrador, viajou pelas cidades de uma Rússia ainda feudal como representante comercial de uma empresa inglesa. Parte de sua obra é dedicada a narrativas que ele foi recolhendo ao longo de viagens.

Em “O narrador", ensaio escrito entre 1928 e 1936, encomendado pela revista Orient et Occident, além da obra de Leskov, Benjamin se ocupará de outros temas na construção de sua teoria da narração. O texto mostra como o espaço social da narração e a tradição por ele constituídas estão em vias de extinção: "é como se estivéssemos privados de uma faculdade de intercambiar experiências" (BENJAMIN, 1996, p. 198).

Benjamin investiga o que teria ocasionado o enfraquecimento da narração. O fim da narrativa tradicional envolve a perda da capacidade de contar, que estaria relacionada, segundo o autor, ao declínio da experiência (Erfahrung) na sociedade moderna. Algo indissociável das mudanças nos processos de produção e compreensão artísticas decorrentes de profundas mutações da percepção coletiva e individual.

\section{0 desencantamento da aura}

O filósofo irá desenvolver uma reflexão sobre os processos de mutação da percepção do sujeito moderno em "A obra de arte na era de sua reprodutibilidade técnica" (1935-1936), ensaio que trata não só de arte ou de técnica, mas principalmente das manifestações e das transformações sociais expressas e materializadas nas técnicas. A obra de arte perde seu caráter Cad. de Pesq. Interdisc. em Ci-s. Hum-s., Florianópolis, Santa Catarina, ISSN 1984-8951 
aurático e ganha um valor de uso social. Tanto "O Narrador", quanto o ensaio sobre a reprodutibilidade técnica tratam do declínio da aura.

O filósofo utiliza o termo "aura" para designar o caráter essencialmente transcendente, fugidio, inesgotável e distante da obra de arte: inapreensível apesar de qualquer proximidade da mesma e ligado ao valor de culto artístico, nos termos da tradicional experiência estética.

As técnicas modernas de reprodução comprometem a expressão aurática da obra de arte, quando buscam captá-la em proximidade e transformá-la em existência serial, reduzindo-a ao status de item de consumo que adquire valor de exposição como material negociável e superficial. Isto significa que o declínio da aura deriva de duas circunstâncias: a procura técnica pela proximidade das coisas e a tendência a superar a unicidade dos elementos mediante a reprodutibilidade. Na proximidade, a unidade e a durabilidade do objeto aurático são substituídas pela repetibilidade e transitoriedade, algo que ocorre também no declínio da narrativa, a partir da ascensão do romance e da informação jornalística explicativa e baseada na efemeridade.

\footnotetext{
Fazer as coisas "ficarem mais próximas" é uma preocupação tão apaixonada das massas modernas como sua tendência a superar o caráter único de todos os fatos através de sua reprodutibilidade. [...] Cada dia fica mais nítida a diferença entre a reprodução, como ela nos é oferecida pelas revistas ilustradas e pelas atualidades cinematográficas, e a imagem. Nesta, a unidade e a durabilidade se associam tão intimamente como, na reprodução, a transitoriedade e a repetibilidade (BENJAMIN, 1996, p. 170).
}

Com a aproximação da realidade mediante as técnicas de reprodução, perde-se a distância natural da aura, mas resta um germe emancipatório. 0 desencantamento da tradição (da cultura, da aura), como foi colocado, também está ligado a uma dimensão libertadora. De acordo com Benjamin, a técnica atualiza o objeto reproduzido, resultando em um abalo violento da tradição, o que por outro lado, constitui uma "renovação da humanidade", ou a renovação da própria natureza da arte. Desse modo, nos parece haver aí um reaparecimento da aura. A contrapelo do que postulavam as teorias dos seus colegas frankfurtianos a respeito da indústria cultural, Benjamin reconheceu nas imagens técnicas - especialmente no cinema - a possibilidade de uma 
aproximação dos indivíduos de um re-encantamento com o mundo, já que a reprodutibilidade técnica possibilitou a proximidade entre a arte e as massas.

Benjamin combateu a estetização política pelo fascismo e a reprodutibilidade técnica da arte na propaganda de mobilização totalitária, mas apontou para a possibilidade de apropriação dos meios de reprodutibilidade técnica na experimentação de outras formas narrativas que não se reduzissem à mera informação ou ao determinismo da causalidade histórica.

No entanto, o filósofo não deixa de reconhecer o empobrecimento cultural decorrente do declínio da experiência no tempo da coletividade. Ele afirma que a experiência aurática na obra de arte é uma experiência na qual a aura aparece em um instante de "retribuição do olhar" com o sujeito observador, algo semelhante à relação do ouvinte (ou leitor) com o narrador. No ato de contemplação da aura, há uma espécie de troca de olhares, de reconhecimento de semelhanças e de correspondências entre o sujeito e a obra contemplada. Isso está relacionado a uma trama entre o olhado e o olhante, à experiência do olhar enquanto experiência limiar na qual ocorre um diálogo entre o que vemos e o que nos olhar. Nas palavras de Benjamin: "perceber a aura de uma coisa significa investi-la do poder de revidar o olhar" (BENJAMIN, 1989, p. 140).

Todavia, o sujeito moderno tem a sua percepção alterada. Não há mais tempo para as velhas histórias, acentua-se a incapacidade de ouvir e consequentemente, não são mais encontradas as comunidades de ouvintes que permaneciam junto aos narradores. O indivíduo não mais reconhece as semelhanças e "as trocas de olhares", o flâneur tende a diluir-se na multidão; o desencantamento da aura corresponde ao desencantamento da percepção humana.

A primeira Grande Guerra consagrou o declínio da experiência e da narração. Os soldados que escaparam das trincheiras voltaram mudos. A barbárie produziu o silêncio aniquilador do sujeito. A experiência das trincheiras, como assinala Benjamin, é destruidora da verdadeira experiência, ela não só reduz o corpo humano a uma massa informe - quando esse é atingido pelo inimigo -, como também impossibilita àquele que dela retorna dizer alguma coisa sobre o que aconteceu. De acordo com Benjamin, os combatentes voltavam do campo de batalha, "mais pobres em experiências Cad. de Pesq. Interdisc. em Ci-s. Hum-s., Florianópolis, Santa Catarina, ISSN 1984-8951 v.15, n.106, p. 5-26 - jan./jun. 2014 
comunicáveis, e não mais ricos" (BENJAMIN, 1996, p. 115). A verdadeira experiência é, com efeito, aquela que faz falar e não a que cala, é a que traduz na linguagem do homem a linguagem muda das coisas. A experiência (Erfahrung) é matéria prima da narração, é o próprio processo de constituição do sujeito nos modos como ele tece a sua história.

Essa tessitura está intrinsecamente relacionada aos movimentos da memória. Todavia, a guerra produziu o silêncio, a memória foi suprimida. $\mathrm{Na}$ grande cidade ocorre algo semelhante. Em "Paris Capital do século XIX", Benjamin chama atenção para o esvanecimento da memória ao detectar o desaparecimento de rastros no contexto urbano. Os interiores burgueses do final do século com seus móveis estofados, tapetes espessos, fotografias, pinturas, e objetos decorativos que sugeriam alguma intimidade desapareceram do espaço público. Esses acessórios tinham a função de destacar a marca do seu proprietário, nas palavras de Benjamin, "habitar significa deixar rastros" (2006, p. 38). Não por acaso o veludo é um dos materiais preferidos dessa época, pois os dedos do seu proprietário deixam nele facilmente os seus rastros.

A ilusão de estar em casa a salvo das engrenagens do mundo moderno acentuou uma separação entre o público e o privado, em decorrência disso, no início do século XX, vários segmentos da arte moderna (o Construtivismo, a Bauhaus, o Cubismo) irão aprofundar a ruptura com a tradição. Artistas e figuras de destaque como Maiakowsky e Aleksei Gan (o ideólogo do Construtivismo), a partir das concepções advindas do Futurismo, defendiam uma noção de progresso, que repudiava a arte burguesa, reduzindo o passado, como propunha Malevich nas formas do Suprematismo, a "grau zero".

Os construtivistas acreditavam na promessa de um novo mundo, no qual o artista, ou o designer, deveria trabalhar junto ao cientista e ao engenheiro. A arte não mais poderia ser representativa, mas informativa, com a função de visualizar os instantes da história em ação, estabelecendo um circuito de comunicação na comunidade, o que estava de acordo com a afirmação de Marx de que o modo de produção da vida material determina os processos sociais, políticos e intelectuais da vida. Os construtivistas acreditavam estar criando uma estética que refletiria sua época. 
Essa atitude, já presente nos pensadores do lluminismo, previa a possibilidade de um mundo neutro, sem ambiguidades, despojado, com mais nitidez. Enfim, na modernidade o veludo cedeu lugar ao vidro, "um material tão duro e tão liso, no qual nada se fixa. É também um material frio e sóbrio. As coisas de vidro não têm nenhuma aura. $O$ vidro é em geral inimigo do mistério. É também o inimigo da propriedade" (BENJAMIN, 1996, p. 117).

Assim como as marcas dos dedos permanecem em uma superfície de veludo, o ouvinte se deixa gravar pelo narrado, também o narrador deixa suas marcas na narrativa, tal como "a mão do oleiro na argila do vaso" (BENJAMIN, 1996, p. 205). Benjamin aproxima Leskov desse mundo de marcas e rastros. Retomando o diagnóstico já feito em seu artigo "Experiência e Pobreza" (1933), o filósofo assinala que o declínio da experiência se deve, fundamentalmente, à lógica do progresso em um mundo dominado pelo desenvolvimento da tecnologia, no qual os indivíduos não deixam rastros, a memória é suprimida, e até mesmo a educação e o conhecimento deixam de se traduzir em experiência. Emerge uma nova forma de pobreza, um déficit de experiência; outra forma de barbárie.

A expropriação da experiência se deve, sobretudo, ao apagamento da tradição na modernidade, vale lembrar o famoso poema de Brecht: "apaguem os rastros!". Essa pobreza de experiência também está relacionada à desvalorização das manifestações culturais, ao esquecimento dos ritos, das nossas experiências limiares, das datas de exceção, dos feriados e das festividades. Em suma, trata-se da escassez de experiências coletivas comunicáveis e plenas de sentido.

Ao relacionar a identidade narrativa à memória e ao tempo, afasta-se da perspectiva de Aristóteles que defendia a objetividade do tempo. Trata-se, como Benjamin propõe, da temporalidade inscrita em nossa linguagem, nos modos como narramos ou poetizamos nossas memórias; na fala comum e na maneira como intuímos o que é o tempo. O Kairós, essa intensificação da temporalidade humana, opõe-se à concepção do Chrónos, tempo cronológico, "homogêneo e vazio". A importância da narração como articulação histórica para conhecer o passado não está no fato do registro, mas na apropriação da reminiscência, que se funda na tradição e se vincula à transmissão de conhecimentos ou de experiências.

Cad. de Pesq. Interdisc. em Ci-s. Hum-s., Florianópolis, Santa Catarina, ISSN 1984-8951 v.15, n.106, p. 5-26 - jan./jun. 2014 
A narrativa tradicional é transmitida por meio da oralidade - patrimônio da poesia épica - cada vez mais sem espaço dentro da sociedade moderna, uma vez que a velocidade e a mecanização comprometeram a escuta das narrativas. A sabedoria é transmitida por meio da oralidade narrativa, capaz de dar conselhos, com toda a riqueza retórica dos gestos, entoações, pausas e ênfases, pois é nas coisas narradas que se encontram as experiências de quem as viveu ou de quem as relata. No contexto em que se estabelecem as relações com a morte e com o tempo, Benjamin afirma: "a memória é a mais épica de todas as faculdades" (1996, p. 210). De acordo com o filósofo, "mnemósine, a deusa da reminiscência, era para os gregos a musa da poesia épica" (1996, p. 211). Benjamin se refere à deusa grega da memória, alargando-lhe o sentido:

\footnotetext{
a reminiscência funda a cadeia da tradição, que transmite os acontecimentos de geração em geração. Ela inclui todas as variedades da forma épica. Entre elas, encontra-se em primeiro lugar a encarnada pelo narrador. Ela tece a rede que em última instância todas as histórias constituem entre si. Uma se articula na outra, como demonstraram todos os outros narradores, principalmente os orientais. Em cada um deles vive uma Sherazade que imagina uma nova história em cada passagem da história que está contando (BENJAMIN, 1996, p. 211).
}

Ao recriar o tempo nas narrativas, imagina-se, recorda-se, em uma organização criadora de memória e de história, de um conhecimento sensível, visual. Vale lembrar a antiga concepção de Heródoto que situava a visão ("testemunha" como o sentido dado à história) como fonte essencial de conhecimento, levando à ideia de que aquele que vê é aquele que sabe (GOFF, 2000, p. 19). Mas, será nos modos de contar/traduzir o que foi testemunhado, ou nos modos de inventar/dizer o tempo que esse ver se constituirá como um saber. Isso implica a faculdade de recriação do real, ou como a humanidade se conta a si mesma, se recria.

O declínio da faculdade de intercambiar experiências na modernidade (e nos tempos atuais, que muitos chamam de "pós-modernidade") decorre da incapacidade de saber contar e, sobretudo, da dificuldade de saber ouvir, isto é, ao "esquecer-se de si mesmo" na tessitura do que se ouve, a escuta se torna leitura. Citando Paulo Freire, o ato de ler implica sempre em uma "re-escrita do lido" (FREIRE, 1982, p. 24). Enquanto leitura, ouvir (ver, sentir, interpretar) é 
condição necessária para contar a história de novo, bem como para (re)construir as narrativas, compartilhar experiências atualizando os saberes tradicionais nos modos de contar.

A arte de narrar é, portanto, a experiência compartilhada de um aprendizado, não é apenas produto da voz. Ouvinte e narrador partilham de uma coletividade, e possuem uma experiência comum: eles se reconhecem na leitura e nas formas de contar a história. Todavia essa experiência se perde, quando no lugar da narrativa se multiplicam dados informativos, que não possuem nenhuma conexão com quem os transmite nem com aquele que os ouve. Assim é que a tradicional experiência narrativa desaparece, e com ela desaparece o narrador que deixava os traços do seu conhecimento nos ouvintes. Desprovido de experiência, o indivíduo não deixa rastros. Com o declínio da experiência, resta a vivência.

Todavia, muito mais que lamentar por uma tradição em vias de desaparecimento, em "O Narrador", Benjamin chama atenção para a atualidade da experiência narrativa como condição da historicidade do ser humano. $\mathrm{Na}$ literatura de Leskov, assim como nos contos de fada e nos provérbios, também nas parábolas de Kafka, sobreviveram ainda elementos de uma narração no sentido tradicional, mas Benjamin também reconhece que com os novos modos de produtividade na sociedade moderna surgem outras possibilidades narrativas, evidenciando o fato de que a faculdade humana de narrar é um construto histórico e que se modifica com as metamorfoses da percepção.

\section{0 sujeito da experiência}

Se a narrativa tradicional se configurou, como foi apontado, em um aprendizado compartilhado, a dificuldade de intercambiar experiências e, consequentemente, o declínio da arte de narrar no mundo moderno, alteraram os modos de sentir e de saber do sujeito aprendente, em formação. Este tem sua experiência subtraída pelo tempo linear esvaziado de sentido, homogêneo e cronológico, pelo acúmulo de informações e saberes, pelo bombardeio das "novidades" geradas nos meios comunicativos, e por uma ação formadora, fundada no pensamento empírico-técnico, fechada na imposição de conhecimentos, em um cenário no qual prevalece a hierarquização dos Cad. de Pesq. Interdisc. em Ci-s. Hum-s., Florianópolis, Santa Catarina, ISSN 1984-8951 
saberes organizados em disciplinas. Nesse contexto, a perda dos elos com a tradição não só se configura como a perda de um "aqui e agora", daquilo que foi soterrado nas ruínas do continuum da história, mas também indica a própria impossibilidade do processo de troca permanente e criadora de conhecimentos que formam o conjunto da experiência, que se modifica ao longo da vida.

No contexto de um cenário no qual o que prevalece são as hierarquias disciplinares, o automatismo e a fragmentação do conhecimento, a educação se distanciou da narração como política ampla de currículo, de formação. $O$ pensamento ilustrado, bem como a educação de massas, cultivou uma razão universal e abstratamente definida. As chamadas psicologias desenvolvimentistas tinham como objetivo central produzir a criança racional (SILVA, 2002, p. 256). Para tanto, universalizaram e abstraíram a noção de razão, ocultando o seu caráter histórico e particular. Desse modo, priorizaramse as narrativas totalizantes que organizam o esquecimento, em detrimento das narrativas que se apresentam como memória, articulando as lembranças dos sujeitos na sua desordem. Em uma sociedade que não deixa rastros, a supressão da memória empobreceu as experiências de aprendizagem, havendo também o empobrecimento de um conhecimento histórico do processo educativo (enquanto processo formativo), na medida em que o "verdadeiro conhecimento" - em uma perspectiva historicista -, ignorou a narrativa que constituía a própria história dos sujeitos em formação.

Isso pode ser verificado no âmbito da própria história do conhecimento histórico. A dicotomia história profana, história sagrada acontecida no Medievo, seguiu-se, no século XVII, a bifurcação: a história-arte e a história-ciência, respectivamente a narração e a pesquisa "definidas e separadas no séc. XIX" (NUNES, 1988, p. 10).

A narrativa da história-arte é definida como a que recria as imagens do passado no presente, no exercício de uma "imaginação projetiva". Pode-se dizer que se trata de um processo criativo do historiador, que se aproxima do artista na arte de narrar, algo semelhante ao modo de contar do narrador tradicional que deixava suas marcas na narrativa, tal como "a mão do oleiro na argila do vaso" (BENJAMIN, 1996, p. 205). Aqui, a experiência do sujeito não está separada dos acontecimentos narrados. Já a história-ciência, refere-se aos acontecimentos objetivamente, de forma distanciada, encadeada, linear; Cad. de Pesq. Interdisc. em Ci-s. Hum-s., Florianópolis, Santa Catarina, ISSN 1984-8951 
seria a etapa preparatória para uma generalização indutiva, caminho para um "verdadeiro conhecimento histórico". Para os adeptos desta última linha, como aponta Pomian (apud NUNES, 1988), aquela imaginação projetiva, ligada à experiência do historiador, deveria ser afastada, não havendo a possibilidade dos entrelaçamentos entre imaginação e razão. Pretendia-se, com isso, a garantia de uma objetividade diante dos fatos; assim, considerava-se o homem sob uma única face: a do domínio racional, como se fosse possível separar o imaginário do pensamento, o homem inteligível do homem sensível. A partir desse modelo de racionalidade, na modernidade, houve a institucionalização do conhecimento histórico no campo das Ciências Sociais. A antiga arte de narrar se perdeu e com ela a experiência do sujeito narrador.

Mas, como já dissemos, surgem outras possibilidades narrativas, bem como iniciativas de retomar a experiência narrativa, na constituição de um pensamento crítico diante do academicismo com que as ciências sociais tratam os seus sujeitos e os seus contextos. Destacamos a perspectiva crítica da educadora Delory-Monberger para quem as narrativas podem ser compreendidas nos âmbitos de uma "bioteca".

\begin{abstract}
O nível de complexidade e de organização na compreensão de uma narrativa está, portanto, vinculado à diversidade das experiências e dos interesses e conhecimento que podem ser mobilizados no momento de sua recepção. Isso significa, então, que só posso ter acesso, na narrativa do outro, ao que constitui para mim objeto de uma experiência biográfica pessoal? $O$ saber e a experiência biográficos que compõem a bioteca formam um sistema contextualizado que integra diversas redes de pertencimentos... inscreve o indivíduo num quadro de referências partilhadas e torna disponível uma soma de saberes experimentais no domínio biográfico (DELORY-MONBERGER, 2008, p. 61).
\end{abstract}

Essa perspectiva vincula a narrativa aos processos formativos, elevando a experiência do sujeito à condição de conhecimento, retomando a ideia de um aprendizado compartilhado. Ainda nas palavras da autora,

é a narrativa que faz de nós o próprio personagem de nossa vida; é ela, enfim, que dá uma história a nossa vida: não fazemos a narrativa de nossa vida porque temos uma história; temos uma história porque fazemos a narrativa de nossa vida (DELORY-MONBERGER, 2008, p. 37).

De acordo com essa argumentação, a formação é experiencial. E, por meio da narrativa, o sujeito tem acesso a esse fenômeno na sua complexidade Cad. de Pesq. Interdisc. em Ci-s. Hum-s., Florianópolis, Santa Catarina, ISSN 1984-8951 v.15, n.106, p. 5-26 - jan./jun. 2014 
existencial e sociocultural. Para citar o pensamento benjaminiano, trata-se dos modos do sujeito dizer o seu eu, afirmando a sua historicidade, revelando assim os seus processos de criação/nomeação do mundo, lembrando que nomear o que fazemos em educação ou em qualquer outro lugar não é só uma questão terminológica, não se trata apenas de produzir um dado empírico, objetivo, informativo.

Entendemos que a perspectiva de Delory-Monberger reforça o capital experiencial dos sujeitos aprendentes, mas a ela acrescentamos o que Arfuch (2010, p. 74) nos diz quando nos mostra que se pode pensar, de forma dialógica, os processos de subjetivação envolvidos nas formas narrativas não apenas na autobiografia, história de vida ou na entrevista biográfica, mas também nos diversos momentos biográficos que surgem nas diversas narrativas, como nas narrativas midiáticas. Há, segundo essa autora, nesses momentos, a busca da plenitude da presença - corpo, rosto, voz - como existência da mítica singularidade do eu, algo que nos dá acesso a uma rota sempre única, para além da dimensão clássica como modo de conhecimento de si e dos outros.

Nesse sentido, a narrativa estaria ligada não apenas às atividades literárias, mas a outras manifestações culturais, conforme Nunes, o termo abrange:

[...] várias espécies de relatos reais e a modalidade escrita biografias, memórias, reportagens, crônicas e historiografia - sobre eventos ou seres reais, que se excluem do nível ficcional [...] [quanto às] formas visuais ou obtidas com meios pictóricos ou escultóricos [...] ou que são obtidas através da imagem cinematográfica e televisionada (NUNES, 1988, p. 6).

Todavia, mesmo que os meios informativos e comunicativos possam se constituir como espaços para as narrativas, é importante ressaltar que a narrativa - enquanto aprendizado compartilhado - se constitui, nas dobras da linguagem, como tradução da experiência do sujeito, e o sujeito da experiência não é necessariamente o sujeito da informação. A narrativa se distingue da informação, segundo Benjamin, ela "não se reduz ao instante em que era nova", nem tampouco pretende ser uma explicação dos acontecimentos. A narrativa é polissêmica, e mantém "coesa a sua força e é capaz de 
desdobramento mesmo depois de passado muito tempo" (BENJAMIN, 1996, p. $62)$.

Assim, há que se estabelecer uma distinção entre experiência e informação. Nas palavras de Bondía (2002, p. 21), "a experiência é o que nos passa, o que nos acontece, o que nos toca. Não o que se passa, não o que acontece, ou o que toca". Esse autor é enfático ao afirmar as diferenças existentes entre o "saber de experiência" e o saber coisas, como quando se está informado. Ao contrário da experiência, a informação é exterior ao sujeito (é o que passa, o que acontece), assim, sabedoria não é informação; e informação não é experiência:

\begin{abstract}
A informação não é experiência. E mais, a informação não deixa lugar para a experiência, ela é quase o contrário da experiência, quase uma antiexperiência. Por isso a ênfase contemporânea na informação, em estar informados, e toda a retórica destinada a constituirmos como sujeitos informantes e informados; a informação não faz outra coisa que cancelar nossas possibilidades de experiência. $O$ sujeito da informação sabe muitas coisas, passa seu tempo buscando informação, o que mais o preocupa é não ter bastante informação; cada vez sabe mais, cada vez está melhor informado, porém, com essa obsessão pela informação e pelo saber (mas saber não no sentido de "sabedoria", mas no sentido de "estar informado"), o que consegue é que nada the aconteça (BONDíA, 2002, p. 21-22).
\end{abstract}

As palavras de Bondía se aproximam do desconforto sentido por Benjamin quando mostrou o paradoxo do mundo moderno que ainda hoje domina: a riqueza dos acontecimentos traduz-se em pobreza da experiência. $E$ ainda: a vertigem das mudanças aceleradas pela técnica é convertida em um sentimento de estagnação. De acordo com Benjamin (1996, p. 118), os indivíduos, quando destituídos de experiência, "nem sempre são ignorantes ou inexperientes. Muitas vezes, podemos afirmar o oposto: eles 'devoraram' tudo, a 'cultura' e os 'homens', e ficaram saciados e exaustos". Esse cansaço é sentido também pelas crianças nos espaços escolares que, com seus métodos e disciplinas, mobilizam a estrutura lógica no sentido de uma determinada forma de conhecimento que delimita, coordena, reduz a parâmetros e gera fadiga.

Em "Manhã de inverno", fragmento de "Infância em Berlim por volta de 1900" (1932-1938), Benjamin evoca as miudezas e as situações cotidianas que revelam, com leveza e certa melancolia, um conhecimento sensível e sutil. Ao 
remontar o quadro incompleto da sua infância, o filósofo traz à baila a sensibilidade de uma época que é apresentada por ele pela ótica da infância, pelos pormenores das múltiplas relações travadas entre as crianças - a magia, os brinquedos e as cores - e a cidade cindida. À imaginação e às observações diárias do mundo o filósofo contrapõe o conhecimento escolar, descrevendo, ao final do texto, o sentimento de estagnação e cansaço que o consome ao chegar à escola:

quando lá chegava, porém, no contato com meu banco, toda aquela fadiga, que parecia ter se dissipado, voltava decuplicada. E com ela o desejo de poder dormir até dizer basta. Devo tê-lo experimentado milhares de vezes, e, mais tarde, de fato, ele se concretizou. Custoume, porém, muito tempo para nisto reconhecer que fora sempre vã a esperança que eu nutria de ter colocação e sustento garantidos (BENJAMIN, 2000, p. 85).

Em "Infância em Berlim", ao redefinir o estilo clássico de narrativa autobiográfica, Benjamin redefine o conceito de sujeito em seus textos. Tratase não mais de um escrito que representasse as lembranças individuais e a história de uma vida, mas de uma escrita que trouxesse a intensidade dessas lembranças, a força das memórias, não apenas pessoal, mas igualmente coletiva. No fragmento acima, a crítica a uma característica específica da escola moderna, que separa educação (enquanto formação) de ensino (instrução), expressa a mutação estrutural da experiência na modernidade. A instrução supõe um saber cristalizado que pode ser transmitido como informação. Ao contrário da transmissão de um conhecimento consolidado, exterior ao sujeito, a formação implica uma compreensão ampliada de um processo de construção do saber nas relações existentes entre indivíduo e coletividade, particular e universal. Nessa perspectiva, a crítica benjaminiana ao sistema escolar aparece na fadiga da criança, no "insondável e fantástico que se confronta com o lógico e bem ordenado do mundo adulto" (SCHLESENER, 2011, p. 129).

É curioso que, na contemporaneidade, se diga que vivemos em uma "sociedade da informação", e esse termo seja sinônimo de "sociedade do conhecimento", ou mesmo "sociedade de aprendizagem", como se o conhecimento se desse sob forma de informação e a aprendizagem se reduzisse a aquisição e ao processamento de informações. Essas metáforas 
cognitivas acabam por denunciar o acúmulo de informações e de saberes que, nas sociedades modernas, se sobrepõem à experiência. Como um suporte (ou depósito) dessas informações e saberes, o sujeito se transforma naquilo que Macedo denominou de "ausência construída" (MACEDO, 2010, p. 170), ou seja, ele é convertido na própria expressão da sua invisibilidade: o sujeito não é mais protagonista de sua própria narrativa, pois dizer o seu eu não é tão importante quanto manter-se informado.

Nesse contexto, os aparatos da imprensa e dos meios comunicativos sacralizaram o par informação/opinião. Isso irá influenciar os modos de pensar a educação e as suas concepções de aprendizagem, principalmente a que os pedagogos e psicopedagogos chamam de "aprendizagem significativa", segundo a qual é preciso informar-se e emitir uma opinião própria sobre o que quer que seja. De acordo com Bondía (2002), esse "opinar" se reduz, na maioria das ocasiões, em estar a favor ou contra, como nas pesquisas de opinião. Esse dispositivo periodístico do saber e da aprendizagem faz com que informação e opinião ocupem todo o espaço do acontecer, impossibilitando a experiência, pois o sujeito individual ou coletivo não é outra coisa senão suporte informado da opinião individual, ou pública. Desse modo, o sujeito mal informado passou a ser considerado como aquele que nada "sabe".

Há nas grandes cidades um aumento enorme de informações, e a incapacidade de se conhecer, julgar, narrar o acontecido. Assim, como sublinha Certeau (2004), a cidade é o teatro de uma guerra de relatos, o que se pode entender tanto como a multiplicidade de vozes que formam a cidade polifônica (CANEVACCI, 2004), quanto a ação dos grandes relatos da TV e da publicidade que esmagam ou atomizam os pequenos relatos de rua ou de bairro.

A obsessão pela novidade é uma característica da modernidade, bem como a velocidade com que são dados os acontecimentos, as notícias, as informações. Isso termina por impedir a conexão significativa dos acontecimentos, impedindo também a memória, pois os acontecimentos, os instantes são rapidamente substituídos por outros, o que nos dá a sensação de uma vivência instantânea, fragmentada, que passa sem deixar vestígios. As práticas educativas da escola moderna se organizam com pacotes curriculares cada vez mais extensos e ao mesmo tempo mais curtos, isto é, são muitas Cad. de Pesq. Interdisc. em Ci-s. Hum-s., Florianópolis, Santa Catarina, ISSN 1984-8951 v.15, n.106, p. 5-26 - jan./jun. 2014 
informações. Mas, o tempo da experiência foi reduzido, daí a sensação de que nada acontece, sensação essa traduzida por Benjamin como uma fadiga, como "o desejo de poder dormir até dizer basta".

Todavia, existe um movimento criador no processo de aprendizagem que se desdobra nas formas de vida, e escapa ao tempo do sempre igual que corre em uma única direção contraindo o presente (o tempo da experiência) e alargando o futuro (o tempo do progresso). Esse movimento profanatório interrompe o continuum da história; está no caminhar lento do flâneur que se demora nos detalhes do que observa, bem como nas brincadeiras infantis como prática de conhecimento do mundo. A experiência sensível dos artistas assemelha-se à experiência das crianças no sentido de mostrar uma forma original e concreta de tratar as coisas e conhecê-las. No fragmento de "Infância em Berlim" que destacamos, conhecimento é, sobretudo, "seguir o rasto da maçã no forno"; e "sentir o aroma espumante que vinha de uma célula da manhã de inverno, mais profunda e recôndita que o próprio perfume da árvore no dia de natal" (BENJAMIN, 2000, p. 85). Esse texto benjaminiano nos mostra como a estrutura da experiência se encontra na do conhecimento, em um intercurso entre imaginação e realidade, sensibilidade e razão, no encantamento de alguns momentos de satisfação e de desejo que retornam à memória. Nos escritos de Benjamin o olhar da criança prefigura a Erfahrunh (experiência) perdida pelo sujeito moderno, agora limitado à Erlebnis (vivência).

Recuperar a "infância" e o seu experimentum linguae, de que nos fala Agamben (2008), é algo que exige abertura, disponibilidade para ouvir com o coração a prosa do mundo. Como nos diz Bondía (2002, p. 23-24),

a experiência, a possibilidade de que algo nos aconteça ou nos toque, requer um gesto de interrupção, um gesto que é quase impossível nos tempos que correm: requer parar para pensar, parar para olhar, parar para escutar, pensar mais devagar, olhar mais devagar, e escutar mais devagar; parar para sentir, sentir mais devagar, demorar-se nos detalhes, suspender a opinião, suspender o juízo, suspender a vontade, suspender o automatismo da ação, cultivar a atenção e a delicadeza, abrir os olhos e os ouvidos, falar sobre o que nos acontece, aprender a lentidão, escutar aos outros, cultivar a arte do encontro, calar muito, ter paciência e dar-se tempo e espaço.

O sujeito da experiência é então um sujeito exposto, vulnerável, que na sua errância se depara com o imprevisível, atravessando territórios 
desconhecidos, ele se perde na cidade, ele chega atrasado. Vale lembrar que em alemão a palavra Erfahrung contém o fahren de viajar, e do alto-alemão fara também deriva Gefahr, perigo, e gefährden, por em perigo (BONDÍA, 2002, p. 25). A palavra experiência, tanto nas línguas germânicas como nas línguas latinas, relaciona-se com travessia. O sujeito da experiência se situa, portanto, em um território de passagem, em um limiar. O sujeito da experiência é um sujeito receptivo, aceitante, interpelado, submetido, o seu contrário seria um sujeito forte, inatingível, anestesiado, apático, que se vale do seu poder e da sua vontade, blindado pela arrogante monocultura do saber e seus critérios únicos de verdade, que definem como incultura ou ignorância os saberes que estão fora dos seus padrões estéticos ou daquilo que foi consagrado como ciência. O saber da experiência é um saber distinto do saber científico e do saber da informação, e possui uma práxis distinta daquela da técnica e do trabalho.

O tempo da experiência é o presente do aqui e agora de uma cognoscibilidade. Porém, a racionalidade baseada na eficácia do pensamento produtivo, a partir da definição de um tempo linear, contraiu o presente e alargou o futuro, com isso o sujeito da experiência se tornou invisível - a experiência do flâneur se tornou improdutiva -, transformando-se em uma ausência. Ao contrair o presente e reduzir a heterogeneidade de tempos ao tempo linear, a lógica do progresso diminuiu a diversidade de experiências. Segundo Santos (s/d, p. 27),

quanto maior for a multiplicidade e diversidade das experiências disponíveis e possíveis (conhecimentos e agentes), maior será a expansão do presente e a contração do futuro [...] essa diversificação e multiplicação ocorre pela via da ecologia dos saberes, do tempo das diferenças, das escalas, dos produtos.

Ainda nas palavras desse autor,

a contração do presente esconde, assim, a maior parte da riqueza inesgotável das experiências sociais no mundo. Benjamin identificou o problema, mas não as suas causas. A pobreza da experiência não é expressão de uma carência, mas antes a expressão de uma arrogância, a arrogância de não sequer ver muito menos valorizar a experiência que nos cerca, apenas porque está fora da razão com que a podemos identificar e valorizar (SANTOS, s/d, p. 10). 
Assim, em uma arqueologia das invisibilidades, Santos propõe, no que designou de "sociologia das ausências", um combate ao "desperdício da experiência". Para esse autor, é preciso reconhecer e tornar inteligíveis as experiências que a tradição filosófica ou científica ocidental ignorou e que, segundo ele, escapam à monocultura do saber científico pela sua variedade $\mathrm{e}$ diversidade. O que Benjamin chamou de "pobreza de experiência", Santos irá conceber como uma "riqueza desperdiçada". De formas diferentes, os dois autores convergem em um ponto: para que não haja um déficit de experiência ou mesmo para que as riquezas das experiências sociais e culturais não sejam desperdiçadas é imprescindível outro modelo de racionalidade.

Santos aponta para a tradução como um procedimento que permite criar inteligibilidade recíproca entre as experiências do mundo. Para o autor, é o que resta para dar sentido a um mundo que perdeu o sentido e a direção, e que se encontra em meio as ruínas do que sobrou do projeto moderno. Trata-se de um trabalho de imaginação epistemológica e democrática, que pretende tornar visíveis as ausências produzidas pela modernidade ocidental. Ao criar constelações de saberes e de práticas o trabalho de tradução, proposto por Santos, aproxima-se da concepção benjaminiana de tradução como interpretação, expõe e desdobra a alteridade valorizando a singularidade, bem como a estranheza dos fenômenos, trata-se de uma recusa à assimilação niveladora que se dispersa na individualidade.

Contrapondo-se ao conhecimento instrumental, homogeneizante, o pensamento benjaminiano se opõe à arrogância do saber científico, acadêmico e disciplinar apontando como alternativa uma epistemologia dialógica que reconhece na linguagem, nas narrativas sem status acadêmico a capacidade de construir um saber do mundo que nunca pertenceu totalmente ao domínio da lógica das disciplinas, mesmo que essa lógica tenha se hegemonizado por séculos. Trata-se de uma perspectiva na qual a cultura está implicada em diversas construções semânticas dos sujeitos humanos; essa perspectiva é então indissociável do par experiência/sentido.

Nesses termos outras formas de compreensão irrompem fora das lógicas cognitivas que conhecemos. Se o experimento científico é previsível, a experiência está no âmbito do indeterminado, possui uma dimensão de incerteza, o seu caminho é o da itinerância, rumo ao desconhecido. O sujeito Cad. de Pesq. Interdisc. em Ci-s. Hum-s., Florianópolis, Santa Catarina, ISSN 1984-8951 v.15, n.106, p. 5-26 - jan./jun. 2014 
da experiência é um nômade aprendente, que se move em suas ambivalências, seus paradoxos e contradições, se mobiliza e, portanto, aprende. 


\section{Referências}

AGAMBEN, G. Infância e história: destruição da experiência e origem da história. Belo Horizonte: Editora UFMGF, 2008.

ARFUCH, L. O espaço biográfico: dilemas da subjetividade contemporânea. Rio de Janeiro: Editora da Universidade do Estado do Rio de Janeiro UERJ, 2010.

BENJAMIN, W. Correspondance. Tradução J. M. Monnoyer. Paris: AubierMontaigne, 1989. 1 e $2 \mathrm{v}$.

Obras escolhidas: Magia e técnica, arte e política. São Paulo:

Editora Brasiliense, 1996.

. Obras escolhidas II: Rua de mão única. São Paulo: Editora Brasiliense, 2000.

Passagens. Belo Horizonte: Editora UFMG, 2006.

BONDÍA, J. L. Notas sobre a experiência e o saber de experiência. Revista Brasileira de Educação, n. 19, p. 20-28, jan./fev./mar./abr. 2002.

BORNHEIM, G. Metafísica e Finitude. Porto Alegre: Ed. Movimento, 1972

CANEVACCI, M. A cidade polifônica: um ensaio sobre a antropologia da comunicação urbana. São Paulo: Studio Nobel, 2004.

CERTEAU, M. de. A invenção do cotidiano: 1. artes de fazer. Petrópolis, RJ: Editora Vozes, 2004.

DELORY-MONBERGER, C. Biografia e educação: figuras do indivíduoprojeto. São Paulo; Natal: Paulus; EDUFRN, 2008.

FREIRE, P. A importância do ato de ler: em três artigos que se completam. São Paulo: Cortez, 1982.

GOFF, J. Le. História e memória. Lisboa: Edições 70, 1982. 1 v.

HOBSBAWM, E. Era dos extremos: o breve século XX. 1914 - 1991. São Paulo: Companhia das Letras, 2008.

MACEDO, R. S. Compreender/mediar a formação: o fundante da educação. Brasília: Liber Livro Editora, 2010.

NUNES, B. Narrativa Histórica e Narrativa Ficcional. In: NUNES, B. et al. Narrativa: Ficção e História. Rio de Janeiro: Imago, 1988. p. 9-35.

ROUANET, S. P. Édipo e o anjo: Itinerários freudianos em Walter Benjamin. Rio de Janeiro: Tempo Brasileiro, 1981. 
SANTOS, B. de S. Para uma Sociologia das ausências e uma sociologia das emergências. s/d. p. 1-50. Disponível em:

<http://www.ces.uc.pt/bss/documentos/sociologia_das_ausencias.pdf>.

Acesso em: 10 ago. 2012.

SCHLESENER, A. H. Os tempos da história: leituras de Walter Benjamin. Brasília: Liber Livro, 2011.

SILVA, T. da S. O sujeito da educação: estudos foucaultianos. Petrópoles, RJ: Vozes, 2002.

Artigo:

Recebido em: 22/07/2013

Aceito em: 24/07/2014 